\title{
The Effect of Composition, Temperature and Post-Irradiation Curing of Bulk Fill Resin Composites on Polymerization Efficiency
}

\author{
Dimitrios Dionysopoulos $^{a *}$, Kosmas Tolidis ${ }^{a}$, Paris Gerasimou $^{a}$ \\ ${ }^{a}$ Department of Operative Dentistry, School of Dentistry, Aristotle University of Thessaloniki, Greece
}

Received: October 10, 2015; Revised: January 25, 2016; Accepted: February 9, 2016

\begin{abstract}
Objectives: To evaluate the polymerization efficiency of bulk fill resin-based composites (RBCs) and how their composition, temperature and post-irradiation polymerization influence the results. Methods and Materials: Eight bulk fill RBCs were investigated. Five specimens for each material were prepared for Vickers hardness measurements. The measurements were performed in three depths from the top of the surface of the specimens $(0,2$ or $4 \mathrm{~mm})$ immediately and $24 \mathrm{~h}$ after polymerization and for the highly viscous bulk fill RBCs after preheating at $54^{\circ} \mathrm{C}$. Statistical analysis was performed using one-way ANOVA and Tukey post hoc tests at $a=0.05$. Results: As the depth increases microhardness values reduce. The Vickers hardness measurements $24 \mathrm{~h}$ after photo-polymerization revealed higher values compared to those obtained immediately after photo-polymerization $(p<0.05)$. There was an increase in microhardness of the $\mathrm{RBC}$ materials when preheated at $54^{\circ} \mathrm{C}$ in comparison with the room temperature specimens $(p<0.05)$.Conclusions: Polymerization efficiency of bulk fill RBCs is affected by their composition and increases with temperature and post-irradiation polymerization.
\end{abstract}

Keywords: Bulk fill resin composites, Resin composite preheating, post-irradiation polymerization, Vickers hardness

\section{Introduction}

Resin-based composites (RBCs) are the most popular restorative materials providing very good esthetics and adequate longevity. When restoring cavities, resin composites should be applied only to increments up to $2 \mathrm{~mm}$ thick to ensure adequate light transmittance and full polymerization of the material ${ }^{1}$. Sufficient polymerization of resin composites is needed to achieve appropriate physical and mechanical properties $^{2}$ and biocompatibility ${ }^{3}$.

In order to overcome and simplify the time-consuming incremental technique of $\mathrm{RBC}$ restorations, a new resin composite category has been recently developed the so-called "bulk fill" RBCs. The bulk fill RBCs are claimed to be curable to a thickness of 4-5 $\mathrm{mm}^{4}$, create a lower polymerization shrinkage stress ${ }^{5}$ and exhibit higher light transmission properties due to reduction of light scattering at the filler-matrix interface by either decreasing the filler amount $^{6}$ or increasing the filler size ${ }^{7}$.

The bulk fill RBCs are further classified into highly viscous and flowable (low-viscosity) resin composites. Highly viscous resin composites contain a greater amount of inorganic fillers compared to flowable resin composites, which adapt better on the cavity walls but exhibit greater polymerization shrinkage and inferior mechanical properties, as a result of their lower filler content. Due to lower mechanical properties of flowable bulk fill resin composites, restorations is recommended to be finished with a 2-mm capping layer of a high-viscosity resin composite when restoring areas which are submitted to occlusal stresses ${ }^{8}$.

*e-mail: ddiondent@gmail.com
The evaluation of surface microhardness of a resin composite is an effective method to indirectly determine the degree of monomer conversion ${ }^{9}$. In the present study, Vickers hardness measurements were performed in order to evaluate the curing efficiency of various bulk fill RBCs. To achieve the acceptable curing efficiency bulk fill materials have to meet the requirement of $\geq 80 \%$ bottom/top percentage microhardness. Flury et al. ${ }^{10}$, who evaluate if depth of cure determined by the ISO 4049 method is accurately reflected with bulk fill materials when compared to depth of cure determined by Vickers microhardness profiles, concluded that the ISO 4049 scraping method overestimated depth of cure compared to depth of cure determined by Vickers hardness profiles. For this reason we used microhardness method for the present study to evaluate curing efficiency.

It has been demonstrated that preheated resin composites exhibit reduced viscosity ${ }^{11}$ and increased polymerization efficiency ${ }^{12}$. Heating the resin composites prior to placement in the cavity and immediately light-curing increases monomer conversion rate and thus the duration of the irradiation period may be reduced ${ }^{13}$. With increased paste temperature, free radicals and developing polymer chains become more fluid as a consequence of decreased paste viscosity and they react to a greater extent, resulting in a more complete polymerization reaction and greater cross-linking ${ }^{14}$. The increase in the degree of polymerization of RBCs may lead to better internal adaptation to cavity walls ${ }^{15}$, improved mechanical properties and increased wear resistance ${ }^{13}$. Taubock et al., ${ }^{16}$ reported that RBC pre-heating significantly reduces shrinkage force formation of high-viscosity bulk-fill and conventional resin 
composites, while maintaining or increasing the degree of monomer conversion, dependent upon the specific composite material used.

Surface hardness will develop over time after lightcuring period which is mainly attributed to post-irradiation polymerization $^{17}$. There are discrepancies in outcomes of previous reports concerning the polymerization kinetics after light-curing of RBCs. Hansen ${ }^{18}$ found that the most of the polymerization reaction takes place during the first minutes after irradiation or one hour after removal of the irradiation source, while Leung et al., ${ }^{19}$ reported that a significant portion of reaction may occur during the first $24 \mathrm{~h}$. Moreover, in a recent study it has been reported a further increase in microhardness of $50-80 \%$ of the immediate readings for some RBC materials in room temperature after $168 \mathrm{~h}^{20}$. The extent of post-irradiation polymerization may be influenced by various intrinsic factors such as monomer composition, availability of free radicals and initial degree of conversion. However, it is not fully understood how these factors affect this phenomenon ${ }^{21}$.

Therefore, the aim of this in vitro study was to evaluate the polymerization efficiency of four highly viscous and four flowable bulk fill resin composites at three depths $(0,2$ and $4 \mathrm{~mm})$ from the surface and to determine if they achieve the curing efficiency requirement for microhardness of $\geq 80 \% \mathrm{VHN}$ of the top surface $(0 \mathrm{~mm})$. Moreover, we investigated how the preheating at $54^{\circ} \mathrm{C}$ of the high-viscosity resin composites and the post-irradiation polymerization after $24 \mathrm{~h}$ may influence the results.

The first null hypothesis of the study (Hol) was that there were no differences in microhardness among the RBC materials of the same measurement depth. The second null hypothesis of the study (Ho2) was that there were no differences in microhardness of the RBC materials when polymerized either at $23^{\circ} \mathrm{C}$ or $54^{\circ} \mathrm{C}$. And the third null hypothesis of the study (Ho3) was that the microhardness of the RBCs was not changed when evaluated immediately or after $24 \mathrm{~h}$.

\section{Materials and methods}

\section{Materials}

Four high-viscosity bulk fill RBCs (X-tra fil - XF, EverX Posterior - EXP, Tetric EvoCeram Bulk Fill - TEB and Beautifil Bulk Restorative - BBR) and four flowable bulk fill RBCs (X-tra base - XB, Beautifil Bulk FlowableBBF, Filtek Bulk Fill - FB and Venus Bulk Fill - VB) were investigated in this study and a conventional nanohybrid resin composite (Filtek Z550 - FZ) was used as a control (Table 1).

Table 1. The technical characteristics of the composite resins investigated.

\begin{tabular}{|c|c|c|c|c|c|c|c|}
\hline Material & Type & Shade & Organic matrix & $\begin{array}{c}\text { Filler load } \\
\text { wt } \%(\text { vol } \%)\end{array}$ & Photoinitiators & Manufacturer & Lot number \\
\hline $\begin{array}{l}\text { Tetric } \\
\text { EvoCeram } \\
\text { Bulk fill } \\
\end{array}$ & $\begin{array}{l}\text { Nanohybrid } \\
\text { Bulk fill }\end{array}$ & $\begin{array}{l}\text { Universal } \\
\text { A shade } \\
\text { (IVA) }\end{array}$ & $\begin{array}{l}\text { Bis-GMA, } \\
\text { UDMA, } \\
\text { Bis-EMA }\end{array}$ & $80 \%(61 \%)$ & $\begin{array}{l}\text { CQ, TPO, } \\
\text { Ivocerin }\end{array}$ & $\begin{array}{l}\text { Ivoclar Vivadent, } \\
\text { Schaan, } \\
\text { Lichtenstein }\end{array}$ & R56348 \\
\hline $\begin{array}{l}\text { Beautifil Bulk } \\
\text { Restorative }\end{array}$ & $\begin{array}{l}\text { Giomer } \\
\text { bulk fill }\end{array}$ & Universal & $\begin{array}{l}\text { Bis-GMA, } \\
\text { UDMA, } \\
\text { Bis-MPEPP, } \\
\text { TEGDMA } \\
\end{array}$ & $87 \%(74.5 \%)$ & CQ & $\begin{array}{l}\text { Shofu Inc, } \\
\text { Kyoto, Japan }\end{array}$ & 01131701 \\
\hline X-tra fill & Bulk fill & Universal & $\begin{array}{l}\text { Bis-GMA, } \\
\text { UDMA, } \\
\text { TEGDMA }\end{array}$ & $86 \%(70.1 \%)$ & N/A & $\begin{array}{l}\text { Voco GmbH, } \\
\text { Cuxhaven, } \\
\text { Germany }\end{array}$ & 1311472 \\
\hline $\begin{array}{l}\text { EverX } \\
\text { Posterior }\end{array}$ & $\begin{array}{l}\text { Fiber- } \\
\text { reinforced } \\
\text { bulk fill }\end{array}$ & Universal & $\begin{array}{l}\text { Bis-GMA, } \\
\text { PMMA, } \\
\text { TEGDMA }\end{array}$ & $74.2 \%(53.6 \%)$ & $\begin{array}{c}\text { CQ, } \\
\text { DMAEMA }\end{array}$ & $\begin{array}{l}\text { G C C o r p, } \\
\text { Tokyo, Japan }\end{array}$ & 1308222 \\
\hline $\begin{array}{l}\text { Venus Bulk } \\
\text { Fill }\end{array}$ & $\begin{array}{l}\text { Flowable } \\
\text { bulk fill }\end{array}$ & Universal & $\begin{array}{l}\text { UDMA } \\
\text { EBADMA }\end{array}$ & $65 \%(38 \%)$ & ТPO & $\begin{array}{l}\text { Heraeus Kulzer, } \\
\text { Hanau, Germany }\end{array}$ & 010032 \\
\hline $\begin{array}{l}\text { Beautifil Bulk } \\
\text { Flowable }\end{array}$ & $\begin{array}{l}\text { Flowable } \\
\text { giomer bulk fill }\end{array}$ & Universal & $\begin{array}{l}\text { Bis-GMA, } \\
\text { UDMA, } \\
\text { Bis-MPEPP, } \\
\text { TEGDMA }\end{array}$ & $72.5 \%(62 \%)$ & CQ & $\begin{array}{l}\text { Shofu Inc, } \\
\text { Kyoto, Japan }\end{array}$ & 09121301 \\
\hline X-tra base & $\begin{array}{l}\text { Flowable } \\
\text { bulk fill }\end{array}$ & Universal & $\begin{array}{l}\text { UDMA, Bis- } \\
\text { EMA }\end{array}$ & $75 \%(58 \%)$ & N/A & $\begin{array}{l}\text { Voco GmbH, } \\
\text { Cuxhaven, } \\
\text { Germany }\end{array}$ & 1310371 \\
\hline $\begin{array}{l}\text { Filtek Bulk } \\
\text { Fill }\end{array}$ & $\begin{array}{l}\text { Flowable } \\
\text { bulk fill }\end{array}$ & Universal & $\begin{array}{l}\text { Bis-GMA, } \\
\text { UDMA, } \\
\text { TEGDMA }\end{array}$ & $64.5 \%(42.5 \%)$ & $\begin{array}{c}\text { CQ, } \\
\text { EDMAB }\end{array}$ & $\begin{array}{l}3 \mathrm{M} \text { E S P E, } \\
\text { St. Paul, MN, } \\
\text { USA }\end{array}$ & N421893 \\
\hline Filtek Z550 & Nanohybrid & A2 & $\begin{array}{l}\text { Bis-GMA, } \\
\text { UDMA, } \\
\text { Bis-EMA, } \\
\text { PEGDMA, } \\
\text { TEGDMA }\end{array}$ & $82 \%(68 \%)$ & CQ & $\begin{array}{l}3 \mathrm{M} \text { E S P E, } \\
\text { St. Paul, MN, } \\
\text { USA }\end{array}$ & N407730 \\
\hline
\end{tabular}




\section{Preparation of the specimens}

The specimens with standardized dimensions $(5 \mathrm{~mm}$ wide, $5 \mathrm{~m}$ long and 2 or $4 \mathrm{~mm}$ high) were prepared for microhardness measurements using a reusable and custom-made stainless steel mold. The resin composite was inserted in the mold in one increment. Polyester strips (Directa AB, SE-194 27, Upplands Vasby, Sweden), $0.05 \mathrm{~mm}$ in thickness, were placed on both sides of the mold and glass microscope slides were placed over the polyester strips and clamped to produce a standardized smooth surface and to remove the excess of the material. Subsequently, the glass microscope slide of the top surface was removed and the top of each specimen irradiated using a LED unit (Elipar S10, 3M ESPE, St. Paul, MN, USA) for $20 \mathrm{sec}$ at $1200 \mathrm{~mW} / \mathrm{cm}^{2}$ with standard curing mode. A radiometer (Demetron L.E.D. Radiometer, Kerr Corp.) was used to verify the output irradiance of the LED unit. The diameter of the light tip is $9 \mathrm{~mm}$ and the wavelength range of the LED is $430-480 \mathrm{~nm}$. There was no distance between the light tip of the LED and the polyester strip of the top surface of the resin composite specimen.

\section{Experimental groups}

The evaluation of the microhardness of the tested bulk fill RBCs was taken place immediately after photo-polymerization as well as $24 \mathrm{~h}$ after dry storage in the dark at room temperature. Moreover, the microhardness of the four highly viscous bulk fill RBCs was also evaluated $24 \mathrm{~h}$ after dry storage in the dark and after preheating at $54^{\circ} \mathrm{C}$. When testing at room temperature, the $\mathrm{RBC}$ materials were allowed to be stabilized at room temperature $\left(23 \pm 1^{\circ} \mathrm{C}\right)$ for $24 \mathrm{~h}$, prior to the test. For preheated specimens, before the measurements the resin composites were placed into a commercially available resin composite warmer (ENA Heat, Micerium SpA, Avegno GE, Italy), thermostatically controlled to $54^{\circ} \mathrm{C}$. Five specimens were prepared for each experimental group $(n=5)$.

\section{Microhardness evaluation}

After photo-polymerization the resin composite specimens were removed from the mold and placed under a microhardness indentation device (HMV-2000, Shimadzu, Tokyo, Japan). A fixed load of $200 \mathrm{~g}$ was applied for $10 \mathrm{~s}$ (Vickers pyramid: diamond right pyramid with a square base and an angle of $a=136^{\circ}$ between the opposite faces at the vertex). Vickers hardness measurements were performed on the top and bottom surfaces of the specimens ( 0 and 2 or $4 \mathrm{~mm}$ depth). Five indentations were made for each specimen's surface, one in the centre of the surface and one in every quadrant ( $>100 \mu \mathrm{m}$ from each other) and were independently averaged and reported in Vickers Hardness Numbers (VHN). Since that the surfaces were in direct contact with a polyester film providing a uniform surface luster, no polishing was performed.

\section{Statistical analysis}

Having preliminarily checked that data distribution was normal in each material and that group variances were homogeneous (Kolmogorov-Smirnov test and Levene test, respectively), the one-way ANOVA was applied to verify the existence of statistically significant betweengroup differences, followed by the Tukey test for post hoc comparisons (Bonferroni corrected). Additionally, the data were analyzed by two-way ANOVA to define how material and temperature affect VHN level. In all the analyses the level of significance was set at $p<0.05$. For the resin composite microhardness measurements, the bottom surface hardness of the specimens should be $80 \%$ of the top surface hardness. Therefore, in the present study the reduction of resin composite microhardness with depth expressed in \%VHN of the top surface of the specimens was also calculated.

\section{Results}

The Vickers hardness measurements for the experimental groups of the study are shown in Fig. 1-3. The Vickers hardness immediately after photo-polymerization at the top surface of the specimens $(0 \mathrm{~mm})$ ranged from $17.36 \pm 0.88$ (FB) to $69.74 \pm 3.09$ (FZ) VHN, at $2 \mathrm{~mm}$ depth from 14.12 \pm 2.30 (FB) to $63.20 \pm 5.21(\mathrm{XF}) \mathrm{VHN}$ and at $4 \mathrm{~mm}$ depth from $12.18 \pm 1.41$ (FB) to $55.84 \pm 2.32$ (XF) VHN. The results indicated that as the depth increases microhardness values reduce. However, this reduction varies depending on the material. The control group of the study (FZ) exhibited the highest microhardness at the top surface and the second highest at $2 \mathrm{~mm}$ depth behind XF. Nevertheless, at $4 \mathrm{~mm}$ depth presented significantly lower microhardness values than all the high-viscosity bulk fill resin composites, BBF and XB $(p<0.05)$. Generally, among the tested bulk fill RBCs the highest Vickers hardness presented XF followed by EXP and the lowest presented VB followed by FB. Most of the flowable bulk fill resin composites exhibited significantly lower VHN (almost the half) than highly viscous bulk fill resin composites in all depths $(p<0.001)$.

The results indicated that there was an increase in microhardness of the RBC materials when preheated at $54^{\circ} \mathrm{C}$ in comparison with the room temperature specimens.

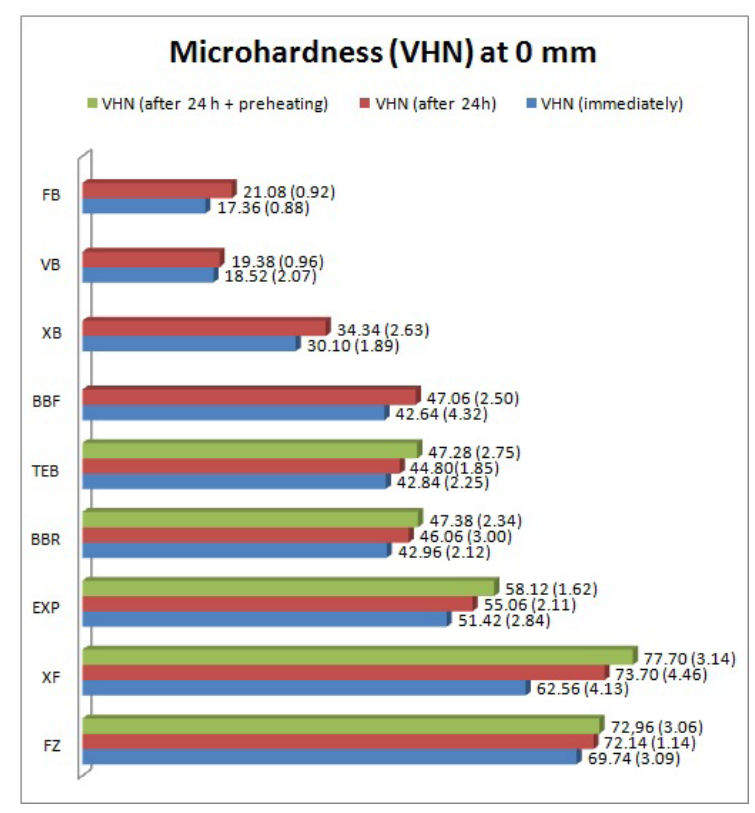

Figure 1. Mean values and standard deviations of microhardness expressed in VHN of all the experimental groups at $0 \mathrm{~mm}$ depth (top surface). 


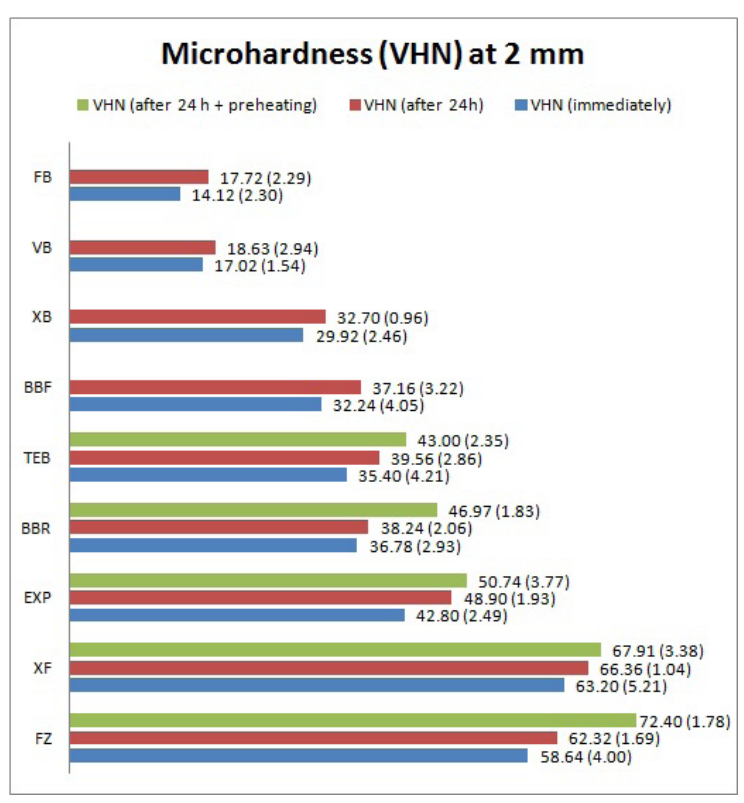

Figure 2. Mean values and standard deviations of microhardness expressed in VHN of all the experimental groups at $2 \mathrm{~mm}$ depth.

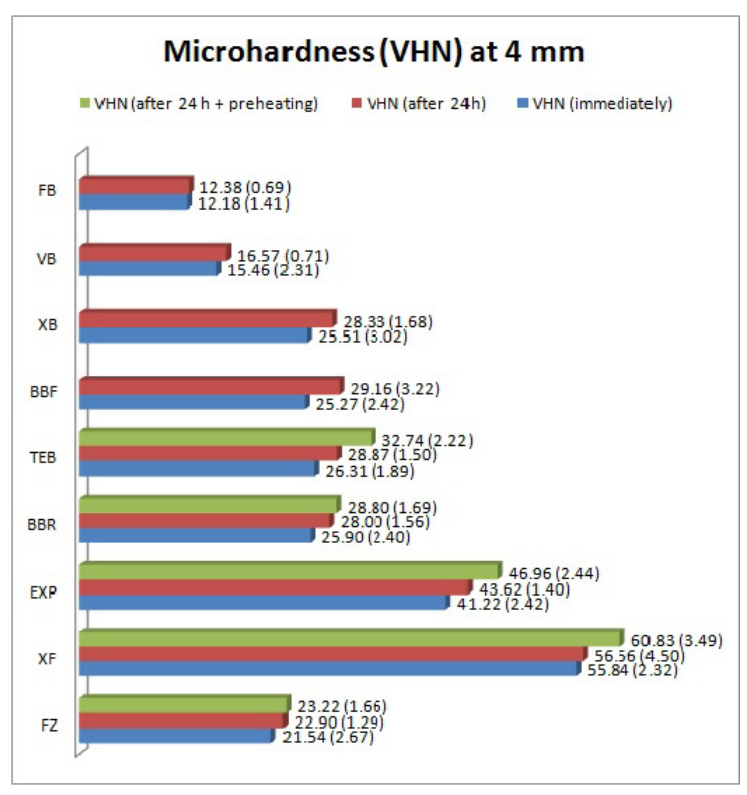

Figure 3. Mean values and standard deviations of microhardness expressed in VHN of all the experimental groups at $4 \mathrm{~mm}$ depth.

Nevertheless, this increase was not statistically significant $(p>0.05)$ in some cases (Table 2). The increase in VHN with temperature ranged between $1.12 \%$ (FZ) to $5.26 \%$ (EXP) at $0 \mathrm{~mm}$ depth, between $2.28 \%$ (XF) to $18.58 \%$ (BBR) at $2 \mathrm{~mm}$ depth and between $1.38 \%$ (FZ) to $11.82 \%$ (TEB) at $4 \mathrm{~mm}$ depth.

The Vickers hardness measurements $24 \mathrm{~h}$ after photo-polymerization revealed higher values compared to those obtained immediately after photo-polymerization in all experimental groups, but the differences were not statistically significant $(p>0.05)$ in some occasions (Table 2). More specifically, the \%VHN increase ranged from $3.32 \%$ (FZ) to $17.64 \%(\mathrm{FB}) \mathrm{VHN}$ at $0 \mathrm{~mm}$ depth, from $3.81 \%$ (BBR) to $20.31 \%$ (FB) VHN at $2 \mathrm{~mm}$ depth and from $1.27 \%$ (XF) to $13.34 \%$ (BBF) VHN at $4 \mathrm{~mm}$ depth. Two-way ANOVA revealed that both material and time after light-curing affect VHN level individually $\left(p_{\text {mat }}<0.001, p_{t}<0.001\right)$ but there is no evidence of a synergistic (interaction) effect of the two $\left(p_{\text {mat }} *_{t}=0.072\right)$.

The reduction of resin composite microhardness with depth for each experimental group expressed in $\% \mathrm{VHN}$ of the top surface of the specimens is presented in Table 2. At $2 \mathrm{~mm}$ depth, all the materials investigated meet or they are very close (75.61-101.02\%) to the threshold value of the requirement for microhardness ( $\geq 80 \% \mathrm{VHN}$ of the top surface) regardless the time of measurement or the temperature. At $4 \mathrm{~mm}$ depth, a further reduction in microhardness is observed for all tested materials compared to $2 \mathrm{~mm}$-depth values. Some of the tested bulk fill RBCs (XF, EXP, XB, VB) again meet or they are very close (76.74-89.26\%) to the threshold value of the requirement but some other (BBR, TEB, BBF, FB) are not so close to the threshold value (58.73-70.16\%). The control material of the study (FZ) exhibited the highest reduction in microhardness (30.89-31.79\% of the top surface) of the RBC materials investigated at $4 \mathrm{~mm}$ depth, regardless the time of measurement or the temperature, although it did not present the lowest VHN.

\section{Discussion}

Many parameters may affect the degree of polymerization of bulk fill RBCs such as their composition (photoinitiators, fillers and organic matrix $)^{6}$, the technical characteristics of the light-curing unit (light intensity, thermal emission, wave length range, diameter of the tip) and the conditions of photo-polymerization (curing mode and exposure time) ${ }^{22}$, the post-irradiation period ${ }^{21}$, the temperature ${ }^{23,24}$ and the incremental thickness of the material ${ }^{25}$.

As statistical analysis revealed the existence of significant differences among the tested bulk fill RBCs with regard to microhardness, the formulated Hol, which states that there were no differences in microhardness among the $\mathrm{RBC}$ materials of the same measurement depth, had to be rejected. This is in agreement with previous reports which investigated the hardness of bulk fill RBCs with different composition $^{21,26}$. These discrepancies may be attributed mainly to the composition of the materials which influences the translucency and as a result the energy density which reach the lower layers of the materials. It is important to mention that the microhardness of a RBC material does not reflect only the extent of polymerization, but other factors such as filler content and filler size, largely affect hardness results. Consequently, the comparisons among the tested materials do not concern the degree of conversion but their hardness as a mechanical property.

As it was mentioned previously, manufacturers of bulk-fill RBCs were able to improve polymerization depth by the use of novel photo-initiator systems along with an increased translucency due to modifications in filler size and content ${ }^{6,7}$. As a matter of fact, in the current study the tested bulk fill RBCs presented significantly lower reduction in microhardness at $4 \mathrm{~mm}$ depth than the control resin 
Table 2. The increase of microhardness $(\% \mathrm{VHN})$ of each tested RBC material after $24 \mathrm{~h}$ and after preheating. The symbol * indicate statistically significant increase in microhardness $(p<0.05)$. Moreover, the reduction of microhardness as the depth increases is also presented for each material and is expressed in $\% \mathrm{VHN}$ of the top surface ( $0 \mathrm{~mm}$ depth). Microhardness requirement: $\geq 80 \% \mathrm{VHN}$ of the top surface.

\begin{tabular}{|c|c|c|c|c|c|}
\hline $0 \mathrm{~mm}$ depth & \multirow{2}{*}{$\begin{array}{c}\% \mathrm{VHN} \\
\text { increase after } \\
24 \mathrm{~h} \\
\end{array}$} & \multirow{2}{*}{$\begin{array}{c}\% \mathrm{VHN} \\
\text { increase after } \\
\text { preheating }\end{array}$} & \multirow{2}{*}{$\begin{array}{c}\text { \%VHN of the top } \\
\text { surface } \\
\text { (immediately) }\end{array}$} & \multirow{2}{*}{$\begin{array}{c}\text { \%VHN of the top } \\
\text { surface } \\
\text { (after 24h) }\end{array}$} & \multirow{2}{*}{$\begin{array}{c}\% \mathrm{VHN} \text { of the } \\
\text { top surface } \\
\text { (after preheating) }\end{array}$} \\
\hline Materials & & & & & \\
\hline FZ & $3.32 \% *$ & $1.12 \%$ & - & - & - \\
\hline $\mathrm{XF}$ & $15.11 \% *$ & $5.15 \% *$ & - & - & - \\
\hline EXP & $6.61 \% *$ & $5.26 \% *$ & - & - & - \\
\hline BBR & $6.73 \% *$ & $2.79 \%$ & - & - & - \\
\hline TEB & $4.37 \%$ & $5.24 \% *$ & - & - & - \\
\hline $\mathrm{BBF}$ & $9.39 \% *$ & - & - & - & - \\
\hline $\mathrm{XB}$ & $12.34 \% *$ & - & - & - & - \\
\hline VB & $4.43 \%$ & - & - & - & - \\
\hline $\mathrm{FB}$ & $17.64 \% *$ & - & - & - & - \\
\hline $2 \mathrm{~mm}$ depth & \multirow{2}{*}{$\begin{array}{c}\% \text { VHN } \\
\text { increase after } \\
24 \mathrm{~h}\end{array}$} & \multirow{2}{*}{$\begin{array}{c}\% \mathrm{VHN} \\
\text { increase after } \\
\text { preheating }\end{array}$} & \multirow{2}{*}{$\begin{array}{c}\text { VHN of the top } \\
\text { surface } \\
\text { (immediately) }\end{array}$} & \multirow{2}{*}{$\begin{array}{c}\text { \%VHN of the top } \\
\text { surface } \\
\text { (after 24h) }\end{array}$} & \multirow{2}{*}{$\begin{array}{c}\text { \%VHN of the } \\
\text { top surface } \\
\text { (after preheating) }\end{array}$} \\
\hline Materials & & & & & \\
\hline FZ & $5.90 \% *$ & $13.92 \% *$ & $84.08 \%$ & $86.39 \%$ & $99.23 \%$ \\
\hline $\mathrm{XF}$ & $4.76 \%$ & $2.28 \%$ & $101.02 \%$ & $90.04 \%$ & $87.40 \%$ \\
\hline EXP & $12.47 \% *$ & $3.63 \%$ & $83.24 \%$ & $88.81 \%$ & $87.30 \%$ \\
\hline BBR & $3.81 \%$ & $18.58 \% *$ & $85.61 \%$ & $83.02 \%$ & $99.13 \%$ \\
\hline TEB & $10.51 \% *$ & $8.00 \% *$ & $82.63 \%$ & $88.30 \%$ & $90.94 \%$ \\
\hline $\mathrm{BBF}$ & $13.24 \% *$ & - & $75.61 \%$ & $78.96 \%$ & - \\
\hline $\mathrm{XB}$ & $8.50 \% *$ & - & $99.40 \%$ & $95.22 \%$ & - \\
\hline VB & $8.64 \%$ & - & $91.90 \%$ & $96.13 \%$ & - \\
\hline FB & $20.31 \% *$ & - & $81.34 \%$ & $81.21 \%$ & - \\
\hline $4 \mathrm{~mm}$ depth & \multirow{2}{*}{$\begin{array}{c}\% \mathrm{VHN} \\
\text { increase after } \\
24 \mathrm{~h}\end{array}$} & \multirow{2}{*}{$\begin{array}{c}\% \mathrm{VHN} \\
\text { increase after } \\
\text { preheating }\end{array}$} & \multirow{2}{*}{$\begin{array}{c}\text { \%VHN of the top } \\
\text { surface } \\
\text { (immediately) }\end{array}$} & \multirow{2}{*}{$\begin{array}{c}\% \text { VHN of the top } \\
\text { surface } \\
\text { (after 24h) }\end{array}$} & \multirow{2}{*}{$\begin{array}{c}\% \text { VHN of the } \\
\text { top surface } \\
\text { (after preheating) }\end{array}$} \\
\hline Materials & & & & & \\
\hline FZ & $5.93 \%$ & $1.38 \%$ & $30.89 \%$ & $31.74 \%$ & $31.79 \%$ \\
\hline $\mathrm{XF}$ & $1.27 \%$ & $7.02 \% *$ & $89.26 \%$ & $76.74 \%$ & $78.29 \%$ \\
\hline EXP & $5.50 \%$ & $7.11 \% *$ & $80.16 \%$ & $79.22 \%$ & $80.80 \%$ \\
\hline BBR & $7.50 \% *$ & $2.78 \%$ & $60.29 \%$ & $60.79 \%$ & $60.78 \%$ \\
\hline TEB & $8.86 \% *$ & $11.82 \% *$ & $61.41 \%$ & $64.44 \%$ & $69.25 \%$ \\
\hline BBF & $13.34 \% *$ & - & $59.26 \%$ & $61.96 \%$ & - \\
\hline $\mathrm{XB}$ & $9.95 \% *$ & - & $84.71 \%$ & $82.50 \%$ & - \\
\hline VB & $6.69 \%$ & - & $83.48 \%$ & $85.50 \%$ & - \\
\hline FB & $1.61 \%$ & - & $70.16 \%$ & $58.73 \%$ & - \\
\hline
\end{tabular}

composite. The photoinitiator system in most of the tested materials is camphorquinone (CQ) except for VB, which contains 2,4,6-tri-methylbenzoyl-diphenylphosphine oxide (TPO) and TEB, which contains TPO and an additional photoinitiator system called Ivocerin, which provides higher photo-curing activity than CQ leading to an enhanced degree of conversion in deeper layers of the material ${ }^{27}$. Nevertheless, in this investigation TEB exhibited higher reduction in Vickers hardness values than XF and EXP, which contain CQ as a photoinitiator, at all depths. This may be explained by the smaller filler size of TEB, which resembles to conventional RBC's and leads to lower translucency ${ }^{28}$.

According to manufacturers, the filler content of the tested highly viscous bulk fill RBCs ranged from 74.2 to $87.0 \mathrm{wt} \%$. These discrepancies in filler content cannot explain the significant differences in the reduction of Vickers hardness values among the highly viscous RBCs which were obtained at $4 \mathrm{~mm}$ depth. As a consequence, the results of our study may be attributed mainly to the different filler size and filler size distribution of the materials. The increased filler size leads to a lower filler-matrix interface and as a result to a decreased light scattering and enhanced light transmittance through the materials ${ }^{7}$. Moreover, differences in the refractive indices between the fillers and the organic matrix of the RBC materials affect their translucency ${ }^{29}$.

The outcomes of the present study indicated that XF and EXP showed the highest Vickers hardness at 2 and $4 \mathrm{~mm}$. The explanation of the results may be the larger fillers $(>20 \mu \mathrm{m})$ that were incorporated in resin matrix of XF compared to the other RBC materials, leading to an enhanced translucency ${ }^{7}$ and regarding the EXP the incorporation of the E-glass fibers which provide better mechanical properties ${ }^{30}$. On the other side, BBR presented the lowest microhardness among the high-viscosity bulk fill RBCs may be due to the increased filler content ( $74.5 \mathrm{vol} \%)$ which leads to lower translucency and higher mechanical properties. 
The variations in monomer composition among $\mathrm{RBC}$ materials may influence their depth of cure. Initial viscosity and flexibility of monomers as well as their ultimate degree of polymerization affect the polymerization efficiency of the RBC materials ${ }^{31}$. Sideridou et al., ${ }^{31}$ demonstrated that UDMA reach higher final \% degree of conversion values than Bis-GMA, combining relatively high molecular weight (UDMA 470.0, Bis-GMA 510.6) with high concentration of double bonds (UDMA $4.25 \mathrm{~mol} / \mathrm{kg}$, Bis-GMA $3.90 \mathrm{~mol} / \mathrm{kg}$ ) and low viscosity (UDMA 23.1 Pa s, Bis-GMA $1200 \mathrm{~Pa} \mathrm{~s}$ ). However, in the present research the tested resin composites do not have main differences in monomer composition that could explain the results (Table 1).

The results of the current investigation revealed that the flowable bulk fill RBCs exhibit significant lower microhardness than high-viscosity bulk fills possibly due to their lower filler content. These outcomes agree with those of previous reports $^{32,33}$. The exception of this evidence in our study was the BBF, which did not present significant differences in Vickers hardness in comparison with $\mathrm{BBR}$ and TEB and the XB (only at $4 \mathrm{~mm}$ depth), which presented similar microhardness with BBR and TEB as well. This may be explained by the high vol $\%$ filler content of BBF (62\%) and XB (58\%), while the other two flowable bulk fills (VB and FB), which presented the lowest Vickers hardness values of all the tested materials, contain 38 and 42 vol\% inorganic fillers, respectively. Concerning the very low microhardness values of VB and $\mathrm{FB}$, a threshold hardness value has to be established in order to verify to what extent the hardness of the RBC restoratives is adequate for clinical use.

Regarding the depth of cure of bulk fill RBCs, in a recent investigation $^{34}$ it has been reported that compared with a conventional resin composite, the high-viscosity bulk-fill materials exhibited only a small but significant increase in depth of cure, whereas the low-viscosity bulk-fill materials produced a significantly larger depth of cure. Moreover, Jang et al., ${ }^{35}$ found that the $\%$ VHN of the top surface of two flowable bulk fill RBCs exceeded $80 \%$ but two highly viscous bulk fills failed to reach the microhardness requirement. Zorzin et al., ${ }^{26}$ who investigated the polymerization properties of various bulk-fill resin composites, in terms of degree of conversion and Vickers hardness and compared them to conventional condensable and flowable resin composites, demonstrated that all the tested bulk fill materials obtained sufficient polymerization properties at $4 \mathrm{~mm}$ depth. It is interesting to mention that in a recent study Tarle et al., ${ }^{36}$ who evaluated the degree of conversion and microhardness of four high-viscosity bulk RBCs reported that although the tested materials exhibited sufficient degree of polymerization at 4 $\mathrm{mm}$ depth, none of them met the microhardness requirement at the same depth. This evidence coincides with the results of the current research, where the tested high-viscosity bulk fill materials failed to meet the microhardness requirement.

In this investigation, the reduction of resin composite microhardness with depth for each experimental group was expressed in \% VHN of the top surface of the specimen. This reduction reflects on the translucency of the materials. In particular, as the translucency of a RBC material increases the energy density at the lower layers also increases and as a result the degree of conversion enhances ${ }^{4}$. According to the results of our study at $2 \mathrm{~mm}$ depth, almost all the tested RBCs meet the threshold value of the requirement for microhardness ( $\geq 80 \% \mathrm{VHN}$ of the top surface) regardless the time of measurement or the temperature. However, at 4-mm depth some of the tested bulk fills again meet the threshold value but some other are not so close to the threshold value maybe due to their lower translucency, which is possibly attributed to differences in filler content and size. For the same reason the control resin composite FZ, as it was expected, presented the lowest \%VHN of the top at 4-mm depth. The decrease of VHN through depths up to $4 \mathrm{~mm}$ varied widely among the bulk fill RBCs and ranged from $10.74 \%$ to $41.27 \%$.

The results obtained from this study demand partially rejection of the Ho2, which states that there were no differences in microhardness of the RBC materials when polymerized either at $23^{\circ} \mathrm{C}$ or $54^{\circ} \mathrm{C}$. The results coincide with those of previous investigators, who found that preheating of resin composites increases their degree of conversion ${ }^{13,23,24}$. Despite the fact that the results of this investigation showed a slight increase in micohardness after preheating for all the materials but in different extent ranged from $1.12 \%$ to $18.58 \%$, in some cases this slight increase was not statistically significant. In a recent research ${ }^{13}$, the evaluation of monomer conversion from infrared spectra at $0 \mathrm{~mm}$ and 2-mm-deep surfaces revealed a strong, positive correlation between temperature and monomer conversion: at $0 \mathrm{~mm}$ $\mathrm{r}^{2}=0.999$ and at $2 \mathrm{~mm} \mathrm{r}^{2}=0.998$. They also reported that the preheating of RBCs at $60^{\circ} \mathrm{C}$ increases the degree of monomer conversion up to $67.3 \%$. Furthermore, Dionysopoulos et al., ${ }^{23}$ found that the increase of microhardness of two preheated conventional resin composites at $54^{\circ} \mathrm{C}$ in comparison with room temperature specimens ranged from $9.6 \%$ to $23.8 \%$. The explanation of this phenomenon may be that preheated RBCs present increased monomer mobility, due to their higher thermal energy, which leads to a lower viscosity and enhanced mobilities of growing chain moieties in the RBC material $^{37}$. As a result, the degree of conversion increases and the surface microhardness, which indirectly expresses this property, also increases.

The results of this study require, in part, the rejection of Ho3, which states that the microhardness of the RBCs was not changed when evaluated immediately or after $24 \mathrm{~h}$. In all the experimental groups a slight increase in Vickers hardness was observed ranged from $1.27 \%$ to $20.31 \%$, but in some cases this increase was not statistically significant. Alshali et al., ${ }^{21}$ who investigate the initial and $24 \mathrm{~h}$ top and bottom microhardness of bulk fill and conventional RBCs demonstrated that all the tested materials exhibited significant increase of microhardness after $24 \mathrm{~h}$ ranged from $9.1 \%$ to $100.1 \%$. Additionally, Par et al., ${ }^{24}$ who assessed the degree of conversion of bulk fill and conventional RBCs immediately and after $24 \mathrm{~h}$ up to $4 \mathrm{~mm}$ depth using Raman spectroscopy reported that immediately after curing the degree of conversion ranged from $59.1 \%$ to $71.8 \%$, while the 24 -hour post-cure values ranged from $71.3 \%$ to $86.1 \%$. This means that a significant increase of the degree of conversion was observed which amounted from $11.3 \%$ to $16.9 \%$.

It is interesting to mention that the amount of the co-monomer TEGDMA is considered to be the most important 
contributor to post-irradiation polymerization of Bis-GMA based resin composites ${ }^{38}$. However, in the current study, the five out of eight tested bulk fill RBCs (BBR, XF, EXP, BBF, and $\mathrm{FB}$ ) included TEGDMA in different extent but it does not seem to affect crucially their microhardness. Possibly, other factors such as filler content, availability of free radicals and initial degree of conversion of the materials may also affect significantly their microhardness ${ }^{21}$.

\section{Conclusions}

According to the results of this in vitro study it could be concluded that:

1. The composition of the bulk fill RBCs affects their polymerization efficiency.

\section{References}

1. Pilo R, Oelgiesser D, Cardash HS. A survey of output intensity and potential for depth of cure among light-curing units in clinical use. Journal of Dentistry. 1999; 27(3):235-241.

2. Ferracane JL, Mitchem JC, Condon JR, Todd R. Wear and marginal breakdown of composites with various degrees of cure. Journal of Dental Research. 1997;76(8):1508-1516.

3. Sideridou ID, Achilias DS. Elution study of unreacted BisGMA, TEGDMA, UDMA, and Bis-EMA from light-cured dental resins and resin composites using HPLC. Journal of Biomedical Materials Research Part B: Applied Biomaterials. 2005;74(1):617-626.

4. Ilie N, Keßler A, Durner J. Influence of various irradiation processes on the mechanical properties and polymerisation kinetics of bulk-fill resin based composites. Journal of Dentistry. 2013;41(8):695-702.

5. Marovic D, Taubock TT, Attin T, Panduric V, Tarle Z. Monomer conversion and shrinkage force kinetics of low-viscosity bulk-fill resin composites. Acta Odontologica Scandinavica. 2015;73(6):474-480.

6. Amirouche-Korichi A, Mouzali M, Watts DC. Effects of monomer ratios and highly radiopaque fillers on degree of conversion and shrinkage-strain of dental resin composites. Dental Materials. 2009;25(11):1411-1418.

7. Ilie N, Stark K. Curing behavior of high-viscosity bulk-fill composites. Journal of Dentistry. 2014;42(8):977-985.

8. Bucuta S, Ilie N. Light transmittance and micro-mechanical properties of bulk fill vs. conventional resin based composites. Clinical Oral Investigations 2014;18(8):1991-2000.

9. Bouschlincher MR, Rueggeberg FA, Wilson BM. Correlation of bottom-to-top surface microhardness and conversion ratios for a variety of resin composite compositions. Operative Dentistry. 2004;29(6):698-704.

10. Flury S, Hayoz S, Peutzfeldt A, Husler J Lussi A. Depth of cure of resin composites: Is the ISO 4049 method suitable for bulk fill materials? Dental Materials. 2012;28(5):521-528.

11. Dionysopoulos D, Tolidis K, Gerasimou P, Koliniotou-Koumpia E. Effect of preheating on film thickness of contemporary composite restorative materials. Journal of Dental Sciences. 2014; 9(4):313-319. doi:10.1016/j.jds.2014.03.006

12. Munoz CA, Bond PR, Sy-Munoz J, Tan D, Peterson J. Effect of pre-heating on depth of cure and surface hardness of lightpolymerized resin composites. American Journal of Dentistry. 2008;21(4):215-222.
2. Most of the tested bulk fill RBCs did not attain 4-mm depth of cure (based on microhardness measurements).

3. Preheating of bulk fill RBCs at $54^{\circ} \mathrm{C}$ increases their microhardness.

4. After $24 \mathrm{~h}$ an increase in resin composite microhardness is observed due to post-irradiation polymerization which is material-depended.

\section{Acknowledgements}

The authors would like to thank Dr. Stavros Dimitriadis for his contribution to the statistical analysis of the data of the present study.

13. Daronch M, Rueggeberg FA, De Goes MF. Monomer conversion of pre-heated composite. Journal of Dental Research. 2005;84(7):663-667.

14. Park SH, Lee CS. The difference in degree of conversion between light-cured and additional heat-cured composites. Operative Dentistry. 1996;21(5):213-217.

15. Dionysopoulos D, Papadopoulos C, Koliniotou-Koumpia E. The evaluation of various restoration techniques on internal adaptation of composites in class $\mathrm{V}$ cavities. International Journal of Biomaterials. 2014;2014:148057. http://dx.doi. org/10.1155/2014/148057.

16. Taubock TT, Tarle Z, Marovic D, Attin T. Pre-heating of highviscosity bulk-fill resin composites: effects on shrinkage force and monomer conversion. Journal of Dentistry. 2015;43(11):13581364.

17. Mohamad D, Young R, Mann A, Watts D. Post-polymerization of dental resin composite evaluated with nanoindentation and micro-Raman spectroscopy. Archives of Orofacial Sciences. 2007;2:26-31.

18. Hansen EK. After-polymerization of visible light activated resins: surface hardness vs. light source. European Journal of Oral Science. 1983;91(5):406-410.

19. Leung RL, Fan PL, Johnston WM. Post-irradiation polymerization of visible light-activated composite resin. Journal of Dental Research. 1983;62:363-365.

20. Marghalani HY. Post-irradiation Vickers microhardness development of novel resin composites. Materials Research. 2010; 13(1):8187. http://dx.doi.org/10.1590/S1516-14392010000100017

21. Alshali RZ, Salim NA, Satterthwaite JD, Silikas N. Postirradiation hardness development, chemical softening, and thermal stability of bulk-fill and conventional resin-composites. Journal of Dentistry. 2015;43(2):209-218.

22. Torno V, Soares P, Martin JM, Mazur RF, Souza EM, Vieira $\mathrm{S}$. Effects of irradiance, wavelength, and thermal emission of different light curing units on the Knoop and Vickers hardness of a composite resin. Journal of Biomedical Materials Research Part B: Applied Biomaterials. 2008;85(1):166-171.

23. Dionysopoulos D, Papadopoulos K, Koliniotou-Koumpia E. Effect of temperature, curing time and filler composition on surface microhardness of composite resins. Journal of Conservative Dentistry. 2015;18(2):114-118.

24. Par M, Gamulin O, Marovic D, Klaric E, Tarle Z. Effect of temperature on post-cure polymerization of bulk-fill composites. Journal of Dentistry. 2014; 42(10):1255-1260. 
25. Flury S, Peutzfeldt A, Lussi A. Influence of increment thickness on microhardness and dentin bond strength of bulk fill resin composites. Dental Materials. 2014;30(10):1104-1112.

26. Zorzin J, Maier E, Harre S, Fey T, Belli R, Lohbauer U, et al. Bulk-fill resin composites: Polymerization properties and extended light curing. Dental Materials. 2015;31(3):293-301.

27. Moszner N, Fischer UK, Ganster B, Liska R, Rheinberger V. Benzoyl germanium derivatives as novel visible light photoinitiators for dental materials. Dental Materials. 2008;24(7):901-907.

28. Ilie N, Bucuta S, Dreaenert M. Bulk-fill resin-based composites: an in vitro assessment of their mechanical performance. Operative Dentistry. 2013; 38(6):618-625.

29. Azzopardi N, Moharamzadeh K, Wood DJ, Martin N, van Noort R. Effect of resin matrix composition on the translucency of experimental dental composite resins. Dental Materials. 2009;25(12):1564-1568.

30. Garoushi S, Vallittu PK, Watts DC, Lassila LVJ. Polymerization shrinkage of experimental short glass fiber-reinforced composite with semi-inter penetrating polymer network matrix. Dental Materials. 2008;24(2):211-215.

31. Sideridou I, Tserki V, Papanastasiou G. Effect of chemical structure on degree of conversion in light-cured dimethacrylatebased dental resins. Biomaterials. 2002;23(8):1819-1829.
32. Arlahlah A, Silikas N, Watts DC. Post-cure depth of cure of bulk fill dental resin-composites. Dental Materials. 2014;30(2):149154.

33. Leprince JG, Palin WM, Vanacker J, Sabbagh J, Devaux J, Leloup G. Physico-mechanical characteristics of commercially available bulk-fill composites. Journal of Dentistry. 2014;42(8):993-1000.

34. Benetti A, Havndrup-Pedersen C, Honore D, Pedersen M, Pallesen U. Bulk-fill resin composites: polymerization contraction, depth of cure, and gap formation. Operative Dentistry. 2015;40(2):190200.

35. Jang JH, Park SH, Hwang IN. Polymerization shrinkage and depth of cure of bulk-fill resin composites and highly filled flowable resin. Operative Dentistry. 2015;40(2):172-180.

36. Tarle Z, Attin T, Marovic D, Andermatt L, Ristic M, Taubock TT. Influence of irradiation time on subsurface degree of conversion and microhardness of high-viscosity bulk-fill resin composites. Clinical Oral Investigations. 2015; 19(4):831-840.

37. Lucey S, Lynch CD, Ray NJ, Burke FM, Hannigan A. Effect of pre-heating on the viscosity and microhardness of a resin composite. Journal of Oral Rehabilitation. 2010;37(4):278-282.

38. Tarumi H, Imazato S, Ehara A, Kato S, Ebi N, Ebisu S. Postirradiation polymerization of composites containing bis-GMA and TEGDMA. Dental Materials. 1999;15(4):238-242. 